\title{
The health and nutrition of young indigenous women in north Queensland - intergenerational implications of poor food quality, obesity, diabetes, tobacco smoking and alcohol use
}

\author{
Robyn McDermott ${ }^{1, *}$, Sandra Campbell ${ }^{1}$, Ming $\mathrm{Li}^{1}$ and Brad McCulloch ${ }^{2}$ \\ 'University of South Australia, GPO Box 2471, Adelaide, South Australia 5001, Australia: ${ }^{2}$ Tropical Public \\ Health Unit, Queensland Health, Cairns, Queensland, Australia
}

Submitted 26 August 2008: Accepted 6 April 2009: First published online 11 June 2009

\begin{abstract}
Objective: To document nutritional status and health behaviours of young indigenous women of childbearing age in rural communities in north Queensland. Design: Cross-sectional survey of 424 Aboriginal and 232 Torres Strait Islander (TSI) women aged 15-34 years, conducted in twenty-three rural and remote communities of far north Queensland in 1999-2000, with follow-up of a smaller cohort ( $n$ 132) in 2006-2007.

Main outcome measures: Weight, waist circumference, intake of fruit and vegetables, smoking, alcohol intake, fasting blood glucose, blood pressure, HDL cholesterol, $\boldsymbol{\gamma}$-glutamyltransferase, red cell folate (RCF), interval weight and waist gain and incidence of diabetes.

Results: Forty-one per cent of Aboriginal and 69\% of TSI had central obesity, $62 \%$ were smokers, $71 \%$ drank alcohol regularly and of those, $60 \%$ did so at harmful levels. One third of Aboriginal and $16 \%$ of TSI women had very low RCF levels. In the group followed up, there was a mean annual waist gain of $1.6 \mathrm{~cm}$ in Aboriginal women and $1.2 \mathrm{~cm}$ in TSI, $0.5 \mathrm{~kg} / \mathrm{m}^{2}$ in BMI and $1.5 \mathrm{~kg}$ in weight. Incidence of new type 2 diabetes mellitus in this cohort was $29 \cdot 1$ per 1000 person-years (py) (95\% CI $14 \cdot 0,52 \cdot 8)$ in Aboriginal women and $13 \cdot 9$ per 1000 py (95\% CI 5·6, 28.5) among TSI. Conclusions: High prevalence and incidence of central obesity and diabetes, poor nutrition, high rates of alcohol use and tobacco smoking together with young maternal age, provide a poor intra-uterine environment for many indigenous Australian babies, and contribute to high perinatal morbidity and future disability. Community level interventions to improve pre-pregnancy nutrition and health behaviours in young women are urgent.
\end{abstract}

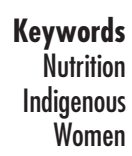

Epidemiological, clinical and physiological research over the past two decades has greatly improved our understanding of the importance of the intra-uterine environment in 'fetal programming' and how this predicts, at a population level, the immediate and long-term health of the next generation. Low birth weight increases risk of diabetes, $\mathrm{CVD}^{(1)}$, renal disease ${ }^{(2)}$ and some cancers in adulthood; low maternal intake of micronutrients increases risk of neurodevelopmental disorders in the offspring; low concentrations of dietary and circulating folate during pregnancy are associated with increased risks of preterm delivery, low birth weight in infants and fetal growth retardation ${ }^{(3)}$; high maternal glycaemia in pregnancy increases perinatal morbidity and also the risk of early obesity and diabetes in the offspring ${ }^{(4)}$; and fetal exposure to maternal tobacco and alcohol is teratogenic $^{(5,6)}$. Babies of teenage mothers, especially those with low educational attainment, are at a higher risk of immediate and long-term ill-health ${ }^{(7)}$.
Indigenous women have babies at a younger age, and their babies suffer higher perinatal mortality and morbidity than non-indigenous babies in north Queensland. In addition, there are important differences between the two ethnic groups which have an impact on health outcomes. Reported prevalence of high BMI and diabetes is higher among the population of Torres Strait Islanders (TSI) than Aborigines ${ }^{(8,9)}$, and there are also differences in reproductive outcomes. More than $25 \%$ of Aboriginal and $15 \%$ of TSI mothers, compared to less than $5 \%$ of nonindigenous mothers in far north Queensland (FNQ), are less than 20 years of age. These young women also have early exposure to sexually transmitted infections and this is accompanied by high rates of alcohol and tobacco use $^{(10)}$. Fifteen per cent of FNQ Aboriginal babies weigh less than $2500 \mathrm{~g}$ at birth compared to $7 \%$ in TSI and nonindigenous groups, and TSI have a higher incidence of large babies (1995-2006 Perinatal Data, Tropical Public Health Unit, Queensland Health). Post-neonatal mortality 
( $28 \mathrm{~d}$ to 12 months of age) is 2.52 times higher among indigenous than non-indigenous Queenslanders ${ }^{(11)}$. Among TSI, high rates of obesity and glycaemia in pregnancy are contributing to a large number of cases of type 2 diabetes mellitus (T2DM) in children, despite better efforts by health services to detect and manage diabetes in pregnancy. The incidence of T2DM among 7-18-yearolds was found to be six times higher for indigenous compared to non-indigenous children in a recent New South Wales survey ${ }^{(12)}$.

Fetal alcohol syndrome (FAS) among indigenous children is significant in northern Australia, with incidence estimated between $1.5 \%$ and $2.76 \%$ of live births ${ }^{(13)}$, and is another entirely preventable cause of permanent physical and mental disability among indigenous children. A recent report from north Queensland suggests that FAS is predicted by maternal self-report of alcohol use prior to and during pregnancy ${ }^{(14)}$.

The present study aimed to estimate the prevalence of potentially preventable risk conditions in indigenous women of childbearing age in FNQ for which there are interventions of demonstrated effectiveness. A 7-year follow-up study in a subsample estimated changes in weight and waist circumference (WC) and incidence of new diabetes in these young women.

\section{Methods}

Between 1999 and 2001, twenty-six rural indigenous communities in FNQ participated in the 'Well Person's Health Check'. Details of methods have been reported elsewhere $^{(15)}$. Briefly, during 1999-2001, all indigenous residents aged 13 years and over in twenty-three small communities were invited to participate through printed media, local radio and word of mouth via the local health service, community council and community groups. Seven years later, those participants who agreed to be followed up were again approached in eleven of the twenty-three communities. The study was approved by the Cairns Base Hospital Human Research Ethics Committee with support from the peak indigenous health organisations, Apunipima Cape York Health Council and the Torres Strait and Northern Peninsula Area Health Council.

\section{Measurements}

Participants were asked to remove footwear and heavy clothing and weighed to the nearest $0 \cdot 1 \mathrm{~kg}$. Height and WC were recorded to the nearest centimetre. BMI was calculated as weight $(\mathrm{kg})$ divided by the height squared $\left(\mathrm{m}^{2}\right)$. Cutoffs were according to WHO criteria ${ }^{(16)}$. Physical activity was measured using a $7 \mathrm{~d}$ recall method in which participants were asked to report daily physical activities of at least $30 \mathrm{~min}$ duration and moderate intensity, performed during the week before their health check.
Drinkers were asked to recall the types and quantities of alcohol consumed in the previous $7 \mathrm{~d}$. 'Risky' drinking was defined as more than two standard drinks per day or more than four on any single occasion, for women. Current smokers were asked how many cigarettes they smoked daily. The physical activity, smoking and alcohol intake measures have been used previously in other studies (International Diabetes Institute) and the dietary questionnaire ( $24 \mathrm{~h}$ recall) and red cell folate (RCF) have been validated against other measures of micronutrient intake and the quality of the diet with respect to fruit and vegetables $^{(17,18)}$.

$\gamma$-Glutamyltransferase (GGT), total cholesterol, HDL cholesterol (HDLC), TAG and glucose were measured on blood collected in the early morning after, at least, an $8 \mathrm{~h}$ fast. Blood pressure (BP) was the average of three measurements taken sitting after 10 min rest. GGT was measured by a kinetic photometric procedure with Cobas Integra 800 (Roche Diagnostic, USA). Blood glucose and blood lipids were measured using photometric enzyme endpoint assay with Cobas Integra 700/400 (Roche Diagnostic). Elevated GGT was defined as GGT $\geq 50 \mathrm{U} / 1$ and a GGT $<50 \mathrm{U} / 1$ as normal for those aged 4 months to 120 years old. The criteria were established by Queensland Pathology Service, the main provider of public sector pathology services in Queensland (http://www.health. qld.gov.au/qhcss/qhps/default.asp).

RCF was measured using the Bayer Advia Centaur automated immunoassay system (Bayer, Australia) by Queensland Health Pathology Service in Brisbane. The reference range for this assay was $295-1800 \mathrm{nmol} / 1$.

Urinary albumin:creatinine ratio (ACR) was measured by immunoassay in $\mathrm{g} / \mathrm{mol}$ from spot urine collected in the early morning after at least an $8 \mathrm{~h}$ fast. Microalbuminuria was defined as ACR $=3 \cdot 4-34 \mathrm{~g} / \mathrm{mol}$, and overt albuminuria as ACR $>34 \mathrm{~g} / \mathrm{mol}^{(19)}$.

Diabetes was defined as either clinical diagnosis of diabetes verified by participants' medical records, or $2 \mathrm{~h}$ glucose tolerance test or fasting blood glucose level $\geq 7 \cdot 0 \mathrm{mmol} / \mathrm{l}$ (WHO criteria ${ }^{(16)}$ ).

Data were analysed using STATA (STATA CORP, College Station, TX, USA). Data were cleaned and the distribution was checked prior to analysis. WC, BMI and RCF were analysed as both continuous and categorical variables based on established cutoffs. Means and sD for continuous variables, and number and percentage for categorical variables, were calculated. Differences between Aboriginal and TSI women were compared using Student's $t$ test or rank-sum test for continuous variables and $\chi^{2}$ test for categorical variables. Statistical significance was set as $P<0 \cdot 05$.

\section{Results}

A total of 2863 adults participated, including non-indigenous and those identifying as both Aboriginal and TSI. 
Table 1 Baseline measures for indigenous women aged 15-34 years in north Queensland rural communities, 1999-2001

\begin{tabular}{|c|c|c|c|c|c|c|}
\hline & \multicolumn{3}{|c|}{ Aboriginal ( $n$ 424) } & \multicolumn{3}{|c|}{ TSI (n 232) } \\
\hline & Mean or $n$ & SD or $\%$ & $95 \% \mathrm{Cl}$ & Mean or $n$ & SD or $\%$ & $95 \% \mathrm{Cl}$ \\
\hline Mean age (years) & $24 \cdot 5$ & $5 \cdot 8$ & $24 \cdot 0,25 \cdot 1$ & $25 \cdot 1$ & $5 \cdot 1$ & $24 \cdot 4,25 \cdot 7$ \\
\hline Diabetes & 13 & $3 \cdot 1$ & $1 \cdot 4,4 \cdot 7$ & 10 & $4 \cdot 3$ & $1 \cdot 7,6 \cdot 9$ \\
\hline Mean WC $(\mathrm{cm})^{*}$ & $86 \cdot 5$ & $15 \cdot 8$ & $85 \cdot 0,88 \cdot 0$ & 98.5 & $15 \cdot 9$ & $96 \cdot 4,100 \cdot 5$ \\
\hline \multicolumn{7}{|l|}{ WC $(\mathrm{cm})^{*}$} \\
\hline$<80$ & 153 & $36 \cdot 1$ & $31 \cdot 5,40 \cdot 7$ & 33 & $14 \cdot 2$ & $9 \cdot 7,18 \cdot 7$ \\
\hline 80-89 & 99 & $23 \cdot 4$ & $19 \cdot 3,27 \cdot 4$ & 39 & $16 \cdot 8$ & $12 \cdot 0,21 \cdot 6$ \\
\hline $90+$ & 172 & $40 \cdot 6$ & $35 \cdot 9,45 \cdot 3$ & 160 & $69 \cdot 0$ & $63 \cdot 0,74 \cdot 9$ \\
\hline Mean BMI $\left(\mathrm{kg} / \mathrm{m}^{2}\right)^{\star}$ & $25 \cdot 0$ & $6 \cdot 4$ & $24 \cdot 2,25 \cdot 4$ & $30 \cdot 7$ & $6 \cdot 9$ & $29 \cdot 8,31 \cdot 6$ \\
\hline \multicolumn{7}{|l|}{ BMI categories $\left(\mathrm{kg} / \mathrm{m}^{2}\right)^{*}$} \\
\hline $18 \cdot 5-25$ & 160 & $37 \cdot 8$ & $33 \cdot 2,42 \cdot 5$ & 47 & $22 \cdot 3$ & $15 \cdot 1,25 \cdot 5$ \\
\hline $25-30$ & 109 & $25 \cdot 8$ & $21 \cdot 6,29 \cdot 9$ & 56 & $24 \cdot 1$ & $18 \cdot 6,29 \cdot 7$ \\
\hline $30+$ & 81 & $19 \cdot 1$ & $15 \cdot 4,22 \cdot 9$ & 122 & $52 \cdot 6$ & $46 \cdot 1,59 \cdot 0$ \\
\hline$<18.5$ & 73 & $17 \cdot 2$ & $13 \cdot 6,20 \cdot 9$ & 7 & $3 \cdot 0$ & $0 \cdot 8,5 \cdot 2$ \\
\hline Smokers & 269 & $63 . \overline{9}$ & $59 \cdot 3,68 \cdot 5$ & 139 & $60 \cdot 0$ & $53 \cdot 6,66 \cdot 2$ \\
\hline Alcohol drinkers & 291 & $70 \cdot 6$ & $66 \cdot 2,75 \cdot 0$ & 160 & $70 \cdot 8$ & $64 \cdot 8,76 \cdot 7$ \\
\hline Risky drinkingt & 187 & $55 \cdot 9$ & $51 \cdot 2,60 \cdot 6$ & 81 & $65 \cdot 1$ & $58 \cdot 9,71 \cdot 2$ \\
\hline Mean serves fruits & 0.9 & $1 \cdot 3$ & $0.8,1 \cdot 0$ & 0.9 & $1 \cdot 1$ & $0.7,1 \cdot 0$ \\
\hline Mean serves vegetables & 1.5 & $1 \cdot 4$ & $1 \cdot 4,1 \cdot 6$ & $1 \cdot 3$ & 1.5 & $1 \cdot 1,1 \cdot 5$ \\
\hline PA sufficient & 78 & $18 \cdot 4$ & $14 \cdot 7,22 \cdot 1$ & 49 & $21 \cdot 1$ & $15 \cdot 8,26 \cdot 4$ \\
\hline Systolic BP $(\mathrm{mmHg})^{\star}$ & $115 \cdot 4$ & $13 \cdot 1$ & $114 \cdot 2,116 \cdot 7$ & $119 \cdot 4$ & $12 \cdot 7$ & $117 \cdot 8,121 \cdot 1$ \\
\hline Diastolic BP (mmHg) & 63.9 & $11 \cdot 1$ & $62 \cdot 8,65 \cdot 0$ & $62 \cdot 8$ & $9 \cdot 8$ & $61 \cdot 5,64 \cdot 1$ \\
\hline Total cholesterol $(\mathrm{mmol} / \mathrm{l})^{*}$ & $4 \cdot 4$ & 0.9 & $4 \cdot 3,4 \cdot 5$ & $4 \cdot 6$ & 0.9 & $4 \cdot 5,4 \cdot 7$ \\
\hline $\operatorname{HDLC}(\mathrm{mmol} /)^{*}$ & $1 \cdot 2$ & 0.3 & $1 \cdot 1,1 \cdot 2$ & $1 \cdot 1$ & 0.3 & $1 \cdot 06,1 \cdot 1$ \\
\hline Mean RCF $(\mathrm{nmol} / \mathrm{l})^{*}$ & 373.9 & $159 \cdot 0$ & $358 \cdot 5,389 \cdot 4$ & $450 \cdot 8$ & $170 \cdot 9$ & $428 \cdot 5,473 \cdot 1$ \\
\hline $\mathrm{RCF}<295 \mathrm{nmol} / /^{*}$ & 134 & $31 \cdot 6$ & $27 \cdot 2,36 \cdot 0$ & 36 & $15 \cdot 5$ & $10 \cdot 8,20 \cdot 2$ \\
\hline Mean GGT $(U / I)^{*}$ & $30 \cdot 3$ & $29 \cdot 7$ & $27 \cdot 4,33 \cdot 2$ & $24 \cdot 5$ & $19 \cdot 3$ & $22 \cdot 0,27 \cdot 0$ \\
\hline GGT $>50 \mathrm{U} / \mathrm{l}(\%)^{*}$ & 68 & $16 \cdot 0$ & $12 \cdot 5,19 \cdot 5$ & 19 & $8 \cdot 2$ & $4 \cdot 6,11 \cdot 7$ \\
\hline Fasting glucose $(\mathrm{mmol} / \mathrm{l})$ & $4 \cdot 8$ & $1 \cdot 3$ & $4 \cdot 6,4.9$ & $4 \cdot 9$ & $1 \cdot 4$ & $4 \cdot 7,5 \cdot 1$ \\
\hline Urine protein $(\mathrm{mg})^{*}$ & $1 \cdot 5$ & $1 \cdot 2$ & $1 \cdot 3,1 \cdot 6$ & $1 \cdot 7$ & 0.8 & $1 \cdot 6,1 \cdot 8$ \\
\hline $\mathrm{ACR}<3.4 \mathrm{~g} / \mathrm{mol}$ & 260 & $61 \cdot 3$ & $56 \cdot 7,66 \cdot 0$ & 147 & $63 \cdot 4$ & $57 \cdot 1,69 \cdot 6$ \\
\hline $\mathrm{ACR}>34 \mathrm{~g} / \mathrm{mol}$ & 114 & $26 \cdot 9$ & $22 \cdot 7,31 \cdot 1$ & 56 & $24 \cdot 1$ & $18 \cdot 6,29 \cdot 7$ \\
\hline
\end{tabular}

TSI, Torres Strait Islanders; WC, waist circumference; PA, physical activity; BP, blood pressure; HDLC, HDL cholesterol; RCF, red cell folate; GGT, $\gamma$-glutamyltransferase; ACR, albumin:creatinine ratio.

*Univariate analysis with $P<0.05$.

$t>2$ per day or $>4$ per day on any occasion.

Based on local census and housing data, the present study achieved a participation rate of $44.5 \%$ with greater participation noted in smaller communities. Participants, overall, were not different demographically from the age and sex distribution of the indigenous population as a whole, based on census data.

Those identifying as both TSI and Aboriginal, and nonindigenous (including of South Sea Islander descent), women reporting a current pregnancy and those aged 35 years and above, and all males, were excluded from this analysis. Thus 232 TSI and 424 Aboriginal women aged 15-34 years were included. Table 1 summarises baseline measures of age, anthropometry, fasting blood glucose, $\mathrm{BP}$, albuminuria (urinary $\mathrm{ACR}>34 \mathrm{~g} / \mathrm{mol}$ ), GGT, RCF and self-reported nutritional intake, alcohol and tobacco use. A total of 716 indigenous women aged $15-34$ years completed baseline check up. Sixty reporting both Aboriginal and TSI descent were not included in the analysis. Mean age was 25 years with no difference between the groups. TSI had significantly higher BMI and WC than Aboriginal women. Tobacco smoking and regular alcohol drinking rates were similar, as was the proportion that reported drinking alcohol at risky levels. $\mathrm{BP}$, fasting glucose, HDLC and proteinuria were similar in the two groups. Aboriginal women were more likely to have raised GGT.

Only twelve women reported 'sufficient' fruit and vegetable intake during the $24 \mathrm{~h}$ recall period (defined as $\geq 2$ fruit and $\geq 5$ vegetables). Mean RCF was low in both groups, and almost one third of Aboriginal and 16\% of TSI women had RCF levels below the reference range.

Table 2 summarises the baseline characteristics of the cohort who were followed up, compared with those who were not followed up. The mean age of those who were not followed up was 24.5 years in both Aboriginal and TSI women. Among the Aboriginal subgroup, there was no difference in age between those followed up and not, while in the TSI subgroup, younger women $(24.5$ years, $95 \% \mathrm{CI}$ $23 \cdot 7,25 \cdot 3 v .26 \cdot 2$ years; $95 \%$ CI $25 \cdot 0,27 \cdot 4 ; P=0 \cdot 02$ ) were less likely to complete the follow-up check.

There were no differences in baseline measurements of weight, WC, blood sugar level, tobacco smoking and alcohol drinking between those completing follow up and those not, in both groups.

Table 3 summarises the 7-year follow-up of a smaller cohort of young women, including mean interval weight and WC change, changes in mean RCF and smoking rates, and incidence of diabetes. 
Table 2 Baseline characteristics $(95 \% \mathrm{Cl})$ of young indigenous women who were followed up at 7 years compared to those not followed up

\begin{tabular}{|c|c|c|c|c|c|c|c|c|}
\hline & \multicolumn{4}{|c|}{ Aboriginal } & \multicolumn{4}{|c|}{ TSI } \\
\hline & \multicolumn{2}{|c|}{ Followed up ( $n$ 53) } & \multicolumn{2}{|c|}{ Not followed up ( $n$ 371) } & \multicolumn{2}{|c|}{ Followed up ( $n 79)$} & \multicolumn{2}{|c|}{ Not followed up ( $n$ 153) } \\
\hline & Mean & $95 \% \mathrm{Cl}$ & Mean & $95 \% \mathrm{Cl}$ & Mean & $95 \% \mathrm{Cl}$ & Mean & $95 \% \mathrm{Cl}$ \\
\hline Mean age (years)* & $24 \cdot 7$ & $23 \cdot 1,26 \cdot 4$ & $24 \cdot 5$ & $23 \cdot 9,25 \cdot 1$ & $26 \cdot 2$ & $25 \cdot 0,27 \cdot 4$ & $24 \cdot 5$ & $23 \cdot 7,25 \cdot 3$ \\
\hline Mean weight (kg) & $66 \cdot 6$ & $60 \cdot 8,72 \cdot 5$ & $63 \cdot 6$ & $61 \cdot 8,65 \cdot 3$ & $83 \cdot 7$ & $79 \cdot 1,88 \cdot 3$ & $81 \cdot 2$ & $78 \cdot 0,84 \cdot 4$ \\
\hline Mean WC $(\mathrm{cm})$ & $89 \cdot 2$ & $84 \cdot 1,94 \cdot 2$ & $86 \cdot 1$ & $84 \cdot 5,87 \cdot 7$ & $100 \cdot 7$ & $97 \cdot 1,104 \cdot 2$ & $97 \cdot 3$ & $94 \cdot 8,99 \cdot 9$ \\
\hline Mean fasting glucose $(\mathrm{mmol} / \mathrm{l})$ & $4 \cdot 7$ & $4 \cdot 6,4 \cdot 8$ & $4 \cdot 8$ & $4 \cdot 6,4 \cdot 9$ & $4 \cdot 7$ & $4 \cdot 6,4 \cdot 9$ & 4.9 & $4 \cdot 7,5 \cdot 2$ \\
\hline Tobacco smoking (\%) & $60 \cdot 4$ & $47 \cdot 1,73 \cdot 7$ & $64 \cdot 4$ & $59 \cdot 5,69 \cdot 3$ & $58 \cdot 2$ & $47 \cdot 3,69 \cdot 2$ & $63 \cdot 9$ & $47 \cdot 9,79 \cdot 8$ \\
\hline Alcohol drinking (\%) & $60 \cdot 4$ & $47 \cdot 1,73 \cdot 7$ & $72 \cdot 1$ & $67 \cdot 5,76 \cdot 8$ & $76 \cdot 5$ & $61 \cdot 2,91 \cdot 0$ & $68 \cdot 8$ & $58 \cdot 4,79 \cdot 3$ \\
\hline
\end{tabular}

TSI, Torres Strait Islanders; WC, waist circumference.

${ }^{*} P<0.05$.

Table 3 Follow-up measures of young Indigenous women in north Queensland, 1999-2006

\begin{tabular}{|c|c|c|c|c|c|c|}
\hline & \multicolumn{3}{|c|}{ Aboriginal ( $n 53)$} & \multicolumn{3}{|c|}{ TSI $(n 79)$} \\
\hline & Mean & SD & $95 \% \mathrm{Cl}$ & Mean & SD & $95 \% \mathrm{Cl}$ \\
\hline Mean interval weight change/year $(\mathrm{kg})^{\star}$ & $1 \cdot 5$ & $1 \cdot 4$ & $1 \cdot 1,1 \cdot 9$ & $1 \cdot 2$ & $1 \cdot 5$ & $0 \cdot 8,1 \cdot 5$ \\
\hline Mean interval BMI change/year $\left(\mathrm{kg} / \mathrm{m}^{2}\right)^{*}$ & 0.5 & $0 \cdot 5$ & $0 \cdot 4,0 \cdot 7$ & $0 \cdot 4$ & $0 \cdot 6$ & $0 \cdot 3,0.6$ \\
\hline Mean interval WC change/year $(\mathrm{cm})^{\star}$ & $1 \cdot 6$ & $1 \cdot 8$ & $1 \cdot 0,2 \cdot 1$ & $1 \cdot 2$ & $1 \cdot 7$ & $0 \cdot 9,1 \cdot 6$ \\
\hline Incidence of diabetes per 1000 py & $29 \cdot 1$ & & $14 \cdot 0,52 \cdot 8$ & $13 \cdot 9$ & & $5 \cdot 6,28 \cdot 5$ \\
\hline
\end{tabular}

TSI, Torres Strait Islanders; WC, waist circumference; py, person-years.

${ }^{*}$ No difference in mean weight gain, mean BMI gain and mean WC gain between groups using rank-sum test.

Aboriginal women were followed up for an average of $7 \cdot 0$ years with a total of $371 \cdot 6$ person-years (py) while TSI women were followed up for a mean of $6 \cdot 6$ years with a total of $521 \cdot 4$ py. The yearly average weight gain in Aboriginal women was $1.5 \mathrm{~kg}$, compared with the $1.2 \mathrm{~kg}$ weight gain in TSI women.

During the follow up, the yearly average BMI gain in Aboriginal women was $0.5 \mathrm{~kg} / \mathrm{m}^{2}$ while it was $0.4 \mathrm{~kg} / \mathrm{m}^{2}$ in TSI women, not significantly different. The yearly average waist gain during the follow up in Aboriginal women was $1.6 \mathrm{~cm}$, compared to the TSI subgroup with a yearly gain of $1.2 \mathrm{~cm}$.

Fifty-three Aboriginal women who did not have diabetes at baseline were followed up for a total of 371.6 py, with ten new diabetes cases diagnosed, giving an incidence rate of $29 \cdot 1(95 \%$ CI $14 \cdot 0,52 \cdot 8)$ per 1000 py. Among seventy-nine TSI women followed up for 521 py, seven new cases of diabetes were found, giving an incidence rate of $13.9(95 \%$ CI 5.6, 28.5) cases per 1000 py.

\section{Conclusions}

The present survey describes a poor picture of health and nutrition among young indigenous women in north Queensland, with escalating rates of obesity and very high incidence of diabetes, combined with extremely poor nutrition and high rates of tobacco and alcohol use. The incidences of new diabetes in the group were three to six times higher than that reported among non-indigenous Australian women aged $25-34$ years during the same period ${ }^{(20)}$ and coincided with rapid increases in central obesity. The combination of these four major risks creates a hazardous intra-uterine environment for the next generation of babies ${ }^{(21)}$ as well as high risk of early-onset diabetes and CVD in the women themselves.

Obesity in pregnancy increases maternal and fetal morbidity. Even moderate overweight increases gestational diabetes and hypertensive disorders of pregnancy, and the risk is higher in subjects with overt obesity. Low Apgar scores, macrosomia and neural tube defects are more frequent in infants of obese mothers than in infants of normal-weight mothers. Maternal obesity increases perinatal mortality. Long-term complications include worsening of maternal obesity and development of obesity in the infant. Cost of hospital prenatal and postnatal care is higher for overweight mothers than for normalweight mothers, and infants of overweight mothers require admission to neonatal intensive care units more often than do infants of normal-weight mothers ${ }^{(22)}$. The intra-uterine environment can have profound effects on the health of the offspring in adulthood. Animal studies demonstrate the powerful influence of the mother's metabolic state on whether the emerging adult develops obesity and hyperinsulinaemia. Importantly, these attributes can be passed on to the next generation nongenetically and can be reversed and prevented $^{(23)}$. Human studies show that children who are large for their gestational age at birth and exposed to an intra-uterine environment of either diabetes or maternal obesity are at increased risk of developing metabolic syndrome. Increasing prevalence of maternal obesity has implications 
for perpetuating the cycle of obesity, insulin resistance and their consequences in subsequent generations ${ }^{(24)}$.

There is increasing evidence from large cohort studies that early fetal growth (the first 12 weeks) predicts birth weight and other important neonatal outcomes. Using precise estimates of gestational age, Bukowski and colleagues found that variation in birth weight was at least partly determined by fetal growth in the first 12 weeks after conception through effects on timing of delivery and fetal growth velocity ${ }^{(25)}$.

A central feature of fetal development is widespread cell division and folate is critical in nucleic acid synthesis. During gestation, marginal or low folate levels, usually due to insufficient dietary intake, can impair cellular growth and replication in the fetus. Neural tube closure normally occurs by week 12 and the periconceptional use of folic acid-containing supplements reduces the occurrence of neural tube defects. Folate intake needs to be sustained after complete closure of the neural tube to decrease the risk of other adverse outcomes including preterm delivery, infant low birth weight and fetal growth retardation. Folate deficiency is also associated with raised maternal blood homocysteine, which in turn is associated with increased habitual spontaneous abortion, pregnancy complications (placental abruption and preeclampsia) and decreased birth weight and gestation duration $^{(3)}$. A recent study comparing traditional Western diets with high-vegetable diets during pregnancy suggested that long-term high vegetable intake favourably affects plasma and red cell folate concentrations throughout pregnancy and reduces the risk of folate deficiency, provided an adequate vitamin $\mathrm{B}_{12}$ supply is ensured ${ }^{(26)}$.

The young indigenous women in the present study reported extremely high rates of binge patterns of alcohol drinking. Apart from FAS associated with maternal binge drinking, which is already a source of much family and community distress, large cohort studies in lower-risk populations are showing more subtle long-term adverse effects in the offspring of intra-uterine exposure to maternal alcohol consumption. For example, a recent study using data from the Avon Longitudinal Study of Parents and Children found that binge patterns of alcohol use (consumption of four or more drinks in a day) in the second and third trimesters of pregnancy were independently associated with higher risks for mental health problems (especially hyperactivity/inattention) in girls at the age of 47 months and in both genders at 81 months ${ }^{(27)}$. More alarming are the findings of a large Australian cohort study looking at intra-uterine 'programming' of alcohol disorders. Adjusting for other biological and social exposures, early in utero exposure to binge patterns of drinking was associated with a threefold risk of developing early and late onset of alcohol disorders at the age of 21 years and exposure later in pregnancy increased the risk by one third. These results suggest at least in part a biological origin of adult alcohol disorders, an association that is not explained solely by maternal drinking or smoking during childhood and adolescence or other intervening factors ${ }^{(28)}$. These findings are supported by animal studies which show, for example, that prenatal exposure may exert long-term effects on the hypothalamic-pituitary-adrenal axis, which may predispose to increased alcohol intake in adult offspring ${ }^{(29)}$.

Tobacco smoking is one of the most important and modifiable risk factors associated with adverse pregnancy and perinatal outcomes, including placenta previa, abruptio placentae, premature rupture of the membranes, preterm birth, intra-uterine growth restriction and sudden infant death syndrome ${ }^{(30)}$. These adverse effects persist into childhood, and in utero exposure to maternal smoking is independently associated with decreased lung function in children of school age, especially for small airway flows ${ }^{(31)}$.

With some exceptions, current measures to promote mother and child health are mainly confined to health services in the study communities, especially antenatal services, and this strategy is needed and should be strengthened. However, many pregnant women in this population do not receive antenatal care until well into the second trimester.

Obesity and micronutrient deficiency in remote indigenous communities are a direct result of food insecurity caused by low incomes and high prices of healthy food in remote areas ${ }^{(32)}$. This should be addressed with broadbased supply-side interventions. Recent improvements to the supply of fresh produce to remote communities, combined with better storage, has resulted in some increases in sales of fruit and vegetables in line with a statewide nutrition strategy ${ }^{(33)}$. High rates of smoking and alcohol use are socially patterned behaviours, which are potentially amenable to locally developed adaptations of proven interventions. To date, some of these have shown promise despite being delivered on a small scale with fixed funding, uncertain implementation and limited effectiveness ${ }^{(34-37)}$. Some differences in risk between these two indigenous groups, demonstrated here, suggest that different strategies may be required for each. For example, central obesity is higher among TSI but Aboriginal women have poorer micronutrient intake, higher GGT and a greater rate of weight gain.

Future clinical programmes and research addressing intrauterine exposures should consider assessments and interventions well before pregnancy ${ }^{(38)}$, be adequately resourced for longer-term results and take account of underlying processes, mechanisms and community context ${ }^{(39)}$.

\section{Acknowledgements}

The present study was supported, in part, by NHMRC Project Grant 279402. The authors have no conflict of interest. The contributions of each author in this work are as follows: R.M. conceived and implemented the study 
and wrote the first draft of the manuscript. S.C. contributed to study design, field work, community report preparation and commented on the manuscript. M.L. contributed to data analysis and manuscript preparation and B.M. contributed to the study design, data collection and management, community report preparation and manuscript preparation. The authors would like to thank the health staff in the participating communities, and to Apunipima and the Torres Strait Islands and NPA Health Councils for their support for the project. In particular, the authors extend their thanks to Phillip Mills, Kerry Arabena and Ross Spark for their assistance, and to all the participants.

\section{References}

1. Barker D (1992) Fetal and Infant Origins of Disease. London: BMJ Books.

2. Hoy W, Rees M, Kile E, Mathews J \& Wang Z (1999) A new dimension to the Barker hypothesis: low birthweight and susceptibility to renal disease. Kidney Int 56, 1072-1077.

3. Scholl TO \& Johnson WG (2000) Folic acid: influence on the outcome of pregnancy. Am J Clin Nutr 71, 1295S-1303S

4. Silverman B, Rizzo T, Cho N \& Metzger B (1998) Long-term effects of the intra-uterine environment: the Northwestern University Diabetes in Pregnancy Center. Diabetes Care 21, Suppl. 2, 142B-149B.

5. O'Leary C (2004) Fetal alcohol syndrome: diagnosis, epidemiology, and developmental outcomes. J Paediatr Child Health 40, 2-7.

6. Dejmek J, Solansky Y, Podrazilova K \& Sram R (2002) The exposure of nonsmoking and smoking mothers to environmental tobacco smoke during different gestational phases and fetal growth. Environ Health Perspect 110, 601-606.

7. King JC (2003) The risk of maternal nutritional depletion and poor outcomes increases in early or closely spaced pregnancies. J Nutr 133, 1732S-1736S.

8. Leonard D, McDermott R, O'Dea K, Rowley K \& Pensio P (2002) Obesity, diabetes and associated cardiovascular risk factors among Torres Strait Islander people. Aust $N Z J$ Public Health 26, 144-149.

9. Daniel M, Rowley K, McDermott R \& O'Dea K (2002) Diabetes and impaired glucose tolerance in Australian Aborigines: prevalence and risk. Diabetes Res Clin Pract 57, 23-33.

10. Miller G, McDermott R, McCulloch B, Fairley C \& Muller R (2003) High prevalence of bacterial STI among young disadvantaged indigenous people in north Queensland, Australia. Sex Transm Infect 79, 332-335.

11. Coory M, Hockey R, Flenady V \& Woodgate P (2006) Postneonatal mortality by rurality and indigenous status in Queensland. J Paediatr Child Health 42, 464-468.

12. Craig M, Femia G, Broyda V, Lloyd M \& Howard M (2007) Type 2 diabetes in Indigenous and non-Indigenous children and adolescents in New South Wales. Med J Aust 186, 497-499.

13. Harris KR \& Bucens IK (2003) Prevalence of fetal alcohol syndrome in the top end of the northern territory. $J$ Paediatr Child Health 39, 528-533.

14. Coyne K, De Costa C, Heazlewood R \& Newman H (2008) Pregnancy characteristics of women giving birth to children with fetal alcohol syndrome in Far North Queensland. Aust N Z J Obstet Gynaecol 48, 240-247.

15. Miller G, McDermott R, McCulloch B, Leonard D, Arabena K \& Muller R (2002) The Well Persons Health Check: a population screening program in indigenous communities in north Queensland. Aust Health Rev 25, 140-151.

16. World Health Organization (1999) Diagnosis and classification of diabetes mellitus. In Definition, Diagnosis and Classification of Diabetes Mellitus and its Complications. Geneva: Department of Noncommunicable Disease Surveillance, WHO.

17. Coyne T, Ibiebele TI, McNaughton S, Rutishauser IH, O'Dea K, Hodge AM, McClintock C, Findlay MG \& Lee A (2005) Evaluation of brief dietary questions to estimate vegetable and fruit consumption - using serum carotenoids and red cell folate. Public Health Nutr 8, 298-308.

18. Hatzis C, Bertsias G, Linardakis M, Scott J \& Kafatos A (2006) Dietary and other lifestyle correlates of serum folate concentrations in a healthy adult population in Crete, Greece: a cross-sectional study. Nutr J 5, 5.

19. Hoy WE \& McDonald S (2004) Albuminuria: marker or target in indigenous populations. Kidney Int 92, S25-S31.

20. Barr E, Magliano D, Zimmet P, Polkinghorne K, Atkins R, Dunstan D, Murray S \& Shaw J (2006) AusDIAB Report. Melbourne: International Diabetes Institute.

21. McMillen I \& Robinson J (2005) Developmental origins of the metabolic syndrome: prediction, plasticity and programming. Physiol Rev 85, 571-633.

22. Galtier-Dereure F, Boegner C \& Bringer J (2000) Obesity and pregnancy: complications and cost. Am J Clin Nutr $\mathbf{7 1}$, 1242S-1248S.

23. Ismail-Beigi F, Catalano PM \& Hanson RW (2006) Metabolic programming: fetal origins of obesity and metabolic syndrome in the adult. Am J Physiol Endocrinol Metab 291, E439-E440.

24. Boney CM, Verma A, Tucker R \& Vohr BR (2005) Metabolic syndrome in childhood: association with birth weight, maternal obesity, and gestational diabetes mellitus. Pediatrics 115, e290-e296.

25. Bukowski R, Smith GCS, Malone FD et al.; FASTER Research Consortium (2007) Fetal growth in early pregnancy and risk of delivering low birth weight infant: prospective cohort study. BMJ 334, 836.

26. Koebnick C, Heins UA, Hoffmann I, Dagnelie PC \& Leitzmann C (2001) Folate status during pregnancy in women is improved by long-term high vegetable intake compared with the average western diet. J Nutr 131, 733-739.

27. Sayal K, Heron J, Golding J, Alati R, Smith GD, Gray R \& Emond A (2009) Binge pattern of alcohol consumption during pregnancy and childhood mental health outcomes: longitudinal population-based study. Pediatrics 123, e289-e296.

28. Alati R, Al Mamun A, Williams GM, O'Callaghan M, Najman JM \& Bor W (2006) In utero alcohol exposure and prediction of alcohol disorders in early adulthood: a birth cohort study. Arch Gen Psychiatry 63, 1009-1016.

29. Lee S, Blanton C \& Rivier C (2003) Prenatal ethanol exposure alters the responsiveness of the rat hypothalamic-pituitaryadrenal axis to nitric oxide. Alcohol Clin Exp Res 27, 962-969.

30. Andres R \& Day N (2000) Perinatal complications associated with maternal tobacco use. Semin Neonatol 5, 231-241.

31. Gilliland FD, Berhane K, McConnell R, Gauderman WJ, Vora H, Rappaport EB, Avol E \& Peters JM (2000) Maternal smoking during pregnancy, environmental tobacco smoke exposure and childhood lung function. Thorax 55, 271-276.

32. Harrison M, Coyne T, Lee A, Leonard D, Lowson S, Groos A \& Ashton BA (2007) The increasing cost of the basic foods required to promote health in Queensland. Med J Aust 186, 9-14.

33. Queensland Health (2002) Eat Well Queensland 2002-12: Smart Eating for a Healthier State. Brisbane: Queensland Health.

34. Campbell S, Duquemin A, Swinbourne A \& McDermott R (2008) North Queensland Tobacco Project Report. Adelaide: University of South Australia. 
35. Ivers R, Castro A, Parfitt D, Bailie R, D'Abbs R \& Richmond R (2006) Evaluation of a multi-component community tobacco intervention in three remote Australian Aboriginal communities. Aust N Z J Public Health 30, 132-136.

36. D'Espaignet E, Measey M, Carnegie M \& Mackerras D (2003) Monitoring the 'Strong Women, Strong Babies, Strong Culture Program': the first eight years. I Paediatr Child Health 39, 668-672.

37. Panaretto K, Lee H, Mitchell M, Larkins S, Manessis V, Buettner P \& Watson D (2005) Impact of a collaborative shared antenatal care program for urban indigenous women: a prospective cohort study. Med J Aust 182, 514-519.

38. Hobel C \& Culhane J (2003) Role of psychosocial and nutritional stress on poor pregnancy outcome. J Nutr 133, 1709S-1717S

39. Campbell NC, Murray E, Darbyshire J, Emery J, Farmer A, Griffiths F, Guthrie B, Lester H, Wilson P \& Kinmonth AL (2007) Designing and evaluating complex interventions to improve health care. BMJ 334, 455-459. 